\title{
BMJ Open Community pharmacists' perception and exposure to drug promotion in Pakistan: a cross-sectional study
}

\author{
Ali Hassan Gillani, ${ }^{1}$ Mingyue Zhao, ${ }^{2,3}$ Azzah Khadim Hussain, ${ }^{4}$ Kiran Munir (D) , \\ Shamaila Masood, ${ }^{6}$ Amna Saeed (i) , ${ }^{7}$ Yu Fang (i) ${ }^{1}$
}

To cite: Gillani AH, Zhao M, Hussain AK, et al. Community pharmacists' perception and exposure to drug promotion in Pakistan: a crosssectional study. BMJ Open 2022;12:e048249. doi:10.1136/ bmjopen-2020-048249

- Prepublication history for this paper is available online. To view these files, please visit the journal online (http://dx.doi. org/10.1136/bmjopen-2020048249).

Received 23 December 2020 Accepted 30 September 2021

Check for updates

(c) Author(s) (or their employer(s)) 2022. Re-use permitted under CC BY-NC. No commercial re-use. See rights and permissions. Published by BMJ.

For numbered affiliations see end of article.

Correspondence to

Dr Yu Fang;

yufang@mail.xjtu.edu.cn

\section{ABSTRACT}

Objective Drug promotion is a factor that promotes the irrational use of drugs and sometimes negatively influences the prescribing/dispensing pattern. So there was a need to assess the views about accepting gifts and attitudes/influence towards drug promotion among community pharmacists in Punjab, Pakistan.

Setting Adopting a preused questionnaire, we conducted a cross-sectional multiple-site survey study. We distributed questionnaires to pharmacists in the community pharmacies to investigate the exposure, scepticism and acceptance to drug promotion as well as their perception about the appropriateness of gifts and to check if they had been taught about dealing with medical representatives. Data were analysed in simple percentages, and the $\chi^{2}$ test was used to evaluate association with demographics. All the analysis was done using SPSS V.23.0.

Results A total $86.9 \%$ (463/533) pharmacists completed the survey. One out of four pharmacists reported being taught about the ethics of drug promotion (26.8\%) and about how to interpret drug promotional material $(25.0 \%)$ and were significantly associated with higher age (age $31 \%-35$ years, $81.9 \%$; $p<0.05$ ). More than two-thirds of the respondents found it appropriate to accept stationery $(73.4 \%)$ and textbooks (70.6\%) as gifts, and only $17.5 \%$ felt it was appropriate to accept direct money. Less than half of the pharmacists $(47.3 \%)$ perceived drug companies were useful for gaining knowledge about new drugs. Majority (76.2\%) thought these drug promotions play a role in the irrational prescribing of antibiotics and $18.6 \%$ dispensed antibiotics due to these promotions.

Conclusion The majority of pharmacists participating in this study felt it was appropriate to receive small value gifts from pharmaceutical companies. Only a small proportion of the respondents was given ethical training and education about drug promotion. Improving the syllabus and updating the pharmacist's knowledge after graduation, as part of continued pharmacy education, will eventually improve the healthcare professionals' capability to act for the patients' welfare.

\section{INTRODUCTION}

Drug promotion (DP) is commonly referred to as all provided information and persuasive endeavours by drug manufacturing companies to healthcare professionals (HCPs), which ultimately leads to

\section{Strengths and limitation of this study}

This is the first study of its kind to investigate pharmacists' perception, knowledge and training in handling drug promotions in Pakistan.

- This is the first study that has indicated the effect of drug promotion on the dispensing of antibiotics.

- This study only evaluated the cross-sectional insight of the effect of drug promotion on dispensing of antibiotics and not the effect of intervention on the antibiotic dispensing rate.

- A self-administered questionnaire was used which may result in under-reporting of responses.

- Implementing proper policies and imprting appropriate training to the pharmacist can reduce the irrational effect of drug promotion.

change in the supply, purchase, use and prescribing of medications. ${ }^{1}$ DP has been recommended to HCPs to improve the information and knowledge about medicine and latest interventions so that medicines could be prescribed and used for patients' welfare. $^{2}$ But the medical marketing cost in the USA has increased to 29.9 billion in 2016 from 17.7 in 1997. The most rapid increase was in direct-to-consumer (DTC) advertising, which increased from \$2.1 billion $(11.9 \%)$ of total spending in 1997 to $\$ 9.6$ billion $(32.0 \%)$ of total spending in 2016. DTC prescription drug advertising increased from $\$ 1.3$ billion (79 000 ads) to $\$ 6$ billion (4.6 million ads (including 663 $000 \mathrm{TV}$ commercials) ). ${ }^{3}$ In the reports of capital lost in Europe in healthcare frauds, it is estimated that the magnitude of corruption and social fraud ranges between $3 \%$ and $8 \%$ of national health expenditures. ${ }^{45}$ In a resolution in the German Bundestag on 'combating corruption in healthcare', a figure of up to $10 \%$ of public health expenditure was quoted for the promotion of drugs. ${ }^{6}$ In 2014 , losing $3 \%, 8 \%$ or $10 \%$ to corruption would mean, for example in 
Austria, given its health expenditures of $€ 36.3$ billion or $11.0 \%$ of gross domestic product, ${ }^{7}$ a loss of $€ 1.1$ billion.

The visits of medical representatives (MRs) to physicians and pharmacists which are combined with other promotional activities such as gifts, sponsored meetings and advertising, affects the attitudes towards the drug company and its medical products. ${ }^{2}$ Interaction and communication between drug company representatives and physicians/pharmacists are of ethical concern because of their pervasive nature and ability to turn into undesirable outcomes. ${ }^{8}$ Evidence suggests that doctors' exposure to such activities has a negative impact on the quality and quantity of drugs they prescribe, resulting in lower quality of care, unjustified risks to patients and more costly prescriptions. ${ }^{910}$ Concerns are that if the DP is inducing doctors to prescribe specific drugs if it is driving pharmacists to dispense expensive drugs when less costly drugs might be better in some cases. ${ }^{11}$

Previous research indicated that doctors/pharmacists who receive gifts are more positive towards the company and are more likely to prescribe/dispense the company's products. ${ }^{12}{ }^{13}$ Selling antimicrobials without prescriptions is common in many lower-income and middle-income countries, and more common in Eastern European countries. ${ }^{14}$ Overall, the determinants that are seen to contribute to the widespread dispensing of antibiotics without a prescription include poor enforcement of legislation, lack of knowledge among pharmacists about infectious disease, the pressure of customers, the business nature of pharmacy, and monetary incentives from pharmaceutical companies. ${ }^{15-17}$ One of the reasons behind the prescription of antibiotics is the external responsibility of the pharmaceutical industry on physicians. ${ }^{18}$ In Pakistan, it is a common practice that the prescription drug is sold in the pharmacy without a prescription, which is strictly prohibited according to local law. The pharmacist dispensing these prescribed drugs has no information of the patient's allergies and, as a result, antibiotics and habit forming medicines are easily accessible without prescription. ${ }^{19}$ Also, several studies have been conducted worldwide to judge the effect of MRs on residents and practicing physicians. ${ }^{11} 2021$ In Pakistan, few studies evaluated the impact of DP on physicians, but none of the studies focused on community pharmacy. ${ }^{22} 23$ Taking into consideration the fact that the community pharmacist is the last and influential person in the healthcare system, our study aimed to investigate the exposure, acceptance or scepticism of CP to DP as well as their perception of the appropriateness of gifts and to determine if pharmacists have had any teaching/training during their study about dealing with MRs and pharmaceutical promotion (PP).

\section{METHODS}

\section{Study area}

Punjab covers $26 \%$ of the total land area of Pakistan and occupies 9 divisions and 36 districts. Also, $60 \%$ of Pakistan's population resides in Punjab. ${ }^{24} 25$ Community pharmacies from three cities (Lahore, Rawalpindi and Sialkot) were chosen from Punjab as they contain a large number of pharmacies with pharmacists appointed. Some of the pharmacies had more than one pharmacist at the time of the survey, so we targeted all of them, but the participation was voluntary. Few chain pharmacies have shifts of duties, and CPs change after 8 hours, so to increase the number of participants, those CPs were visited during different time frames. The selection of pharmacies was random from all the three cities, and we tried to target the pharmacies from different geographical regions. Pharmacies of small, middle and large scales were also included. A total of 331 pharmacies was targeted, and 533 pharmacists were approached. The number of pharmacies and pharmacists approached and participating are mentioned in figure 1 .

\section{Survey tool and its distribution}

The study was a multisite randomised cross-sectional survey. We used self-administered questionnaires which contained information from previously published literature (online supplemental file 1). ${ }^{2}$ The survey was conducted from January to March and then from April to June 2020 in three cities of Punjab. The community pharmacist $(\mathrm{CP})$ was queried about five DP related issues, namely: (1) Demographic data of the CP (age, gender and residence); (2) Pharmaceutical company exposure to training about DP and interactions with MRs; (3) Perceptions of the suitability of various drug company prizes which was assessed by 13 items on a 3-point scale (appropriate, inappropriate and neutral); and (4) Attitudes about PP measured as agreement with 10 statements (5 revealing acceptance of DP and 5 revealing scepticism) on a 3-point scale (agree, disagree and neutral) and 3 statements about the influence of DP on dispensing of drugs on a 3-point scale (yes, no uncertain).

The data collection tool was further checked for consistency and validity on our study population. Before we finalised the questionnaire, we conducted a pilot study in selected areas among 10 individuals from each city. These individuals were asked for the assessment of wording, appropriateness and comprehension of the questionnaire. The pretest data were not included in the final analysis.

\section{Patient and public involvement}

No patient involved.

\section{Ethical approval}

Written consent was obtained from all the willing participants with the assurance that their name and the name of their pharmacy will remain confidential.

\section{Data management and analysis}

The agreement to statements was determined by combining those who responded 'Disagree' and 'Neutral' and numbered as 0 , whereas 'Agree' was given a score of 1 . Similarly, those who answered 'Neutral' and 


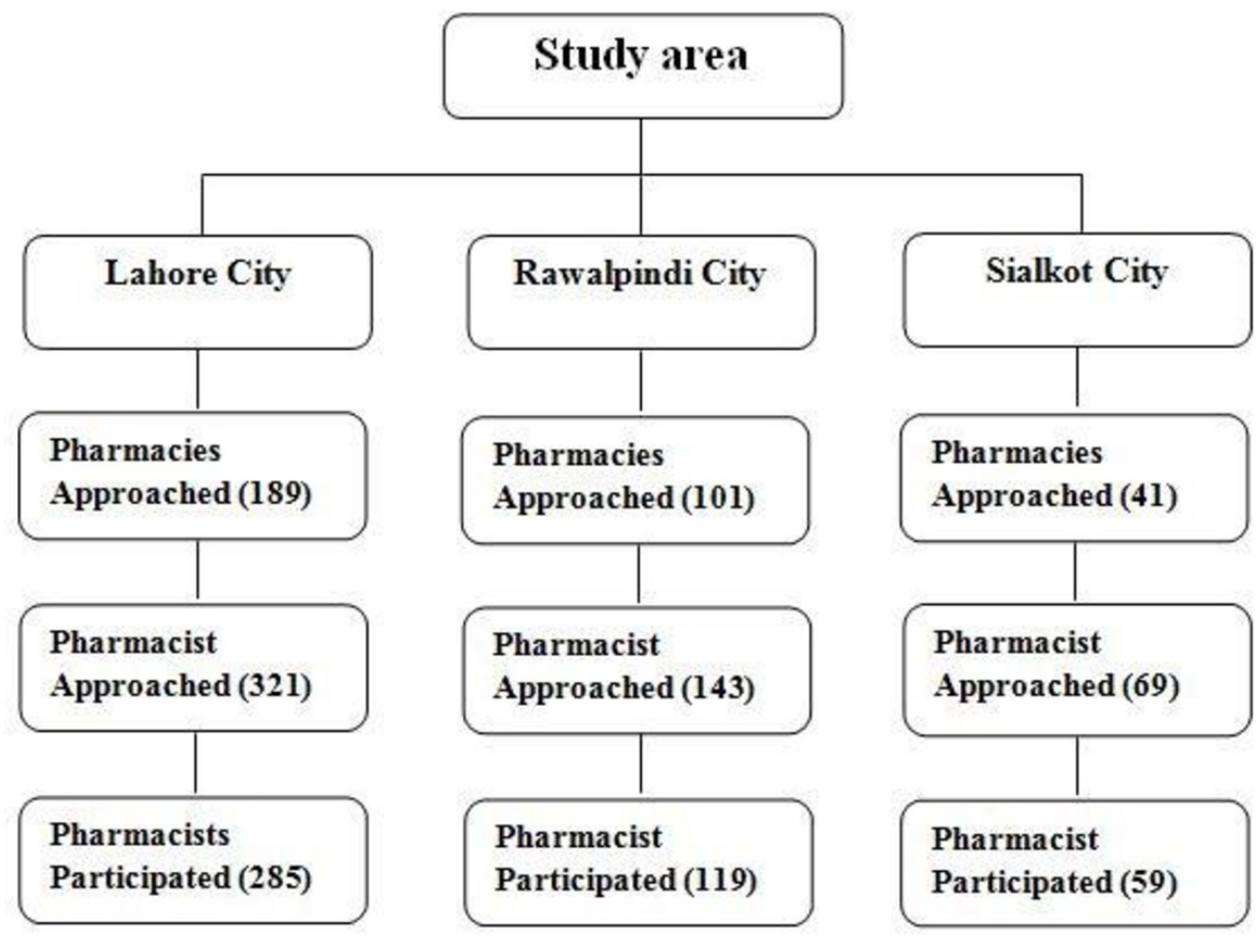

Figure 1 Number of pharmacies and pharmacists approached and participated.

'Inappropriate' were scored 0, and those who said 'Appropriate' are numbered as 1. We used SPSS V. 21.0 statistical software (SPSS, Chicago, Illinois, USA) for analysis. The $\chi^{2}$ test was used for the comparison of proportions. The significance level was set as $\mathrm{p}<0.05$.

\section{RESULTS}

\section{Demographic details}

A total of 533 pharmacists in 331 pharmacies was approached, and 463 completed the survey with a response rate of $86.9 \%$. The mean age of the respondents was 26.8 years $( \pm$ SD 3.1$)$, a majority $(82.1 \%)$ of them was in the age group 26-30 years, and their mean experience was 2.7 years $( \pm$ SD 1.3$)$ years. A large proportion of our study population was men $(72.4 \%)$ and from an urban locality $(91.8 \%)$. The description is given in table 1 .

\begin{tabular}{|c|c|}
\hline Characteristics & Number of participants (\%) \\
\hline \multicolumn{2}{|l|}{ Gender } \\
\hline Male & $335(72.4)$ \\
\hline Female & $128(27.6)$ \\
\hline \multicolumn{2}{|c|}{ Age 26.8 years $( \pm S D 3.1)$} \\
\hline $20-25$ & $159(34.3)$ \\
\hline $26-30$ & $221(47.7)$ \\
\hline $31-35$ & $83(17.9)$ \\
\hline \multicolumn{2}{|c|}{ Years of experience $2.7( \pm$ SD 1.3) } \\
\hline $1-3$ & 339 (73.2) \\
\hline $4-6$ & $124(26.8)$ \\
\hline
\end{tabular}

Table 2 represents the view on the appropriateness of accepting different promotional gifts by the pharmacists. The majority of the participants felt it was appropriate to take the stationery items $(73.4 \%)$, and almost a similar number of pharmacists $(70.6 \%)$ deemed it appropriate to receive textbooks from MRs. Most of the pharmacists $(82.5 \%)$ said it was inappropriate to make direct money from MRs.

More than two-thirds of of the MRs approached were pharmacists $(69.5 \%)$ during the working hours of the

Table 2 Proportion of pharmacists that deemed it appropriate to accept gifts from MRs

\begin{tabular}{lll}
\hline Sr No & Activity/gifts & Appropriate (\%) \\
\hline 1 & Meals & $107(23.1)$ \\
\hline 2 & Gifts (>Rs5000) & $103(22.2)$ \\
\hline 4 & Gifts (Rs3000-5000) & $139(30.0)$ \\
\hline 5 & Gifts (<Rs3000) & $248(53.6)$ \\
\hline 6 & Drug samples & $169(36.5)$ \\
7 & Social trips & $102(22.0)$ \\
8 & International holidays & $100(21.6)$ \\
9 & Pen/notepad & $283(61.1)$ \\
9 & Conference registration fee & $192(41.5)$ \\
11 & Travel to conference & $189(40.8)$ \\
\hline 12 & Stationary & $327(70.6)$ \\
\hline 13 & Money & $340(73.4)$ \\
\hline
\end{tabular}

MR, medical representative. 
pharmacy settings. A fourth (25.0\%) of the respondents said that they had received teaching during the course of their degree regarding handling the MRs and the same number were friends with the MRs. The pharmacists' response was very low in terms of being approached by the MRs in the pharmacy institution (18.1\%).

Among the different demographic properties, gender had no significant difference with any of the items $(p>0.05)$, whereas the age group 31-35 years showed a significantly high proportion in terms of receiving ethical training ( $45.8 \%$ in $31-35$ years vs $31.1 \%$ in $20-25$ years; $\mathrm{p}<0.001)$ and teaching about how to tackle the MRs ( $81.9 \%$ in $31-40$ years vs $0.0 \%$ in $20-25$ years; $p<0.001)$. Also, they had a significantly higher number of MRs as friends $(41.0 \%)$ as compared with the $20-25$ years age group (21.4\%; $\mathrm{p}<0.001$ ) (table 3$)$.

The perception of pharmacists towards $\mathrm{PP}$ is shown in table 4. At a glance, the data showed that a higher proportion of pharmacists was sceptical about accepting DP.

\section{Demographic association with a statement indicating the acceptance, scepticism and influence}

In terms of demographic difference, a significantly high proportion of men thought it was OK to 'accept gifts from drug companies because drug companies have minimal influence on staff' ( $19.4 \%$ men vs $11.7 \%$ women; $\mathrm{p}=0.038$ ). A high proportion of men felt that 'Most talks sponsored by drug companies are helpful and educational' (31.9\% men vs $22.7 \%$ women; $p=0.027$ ). Similarly, the $31-35$ years age group showed a significant high response for 'accept gifts from drug companies because drug companies have minimal influence on staff' $(31.3 \%$ vs $19.5 ; \mathrm{p}=0.000)$ and 'Most talks sponsored by drug companies are helpful and educational' ( $38.6 \%$ vs $18.2 \%$; $\mathrm{p}=0.000$ ).

Respondents in the 31-35 years age group showed a significantly lower degree of compliance to the statement 'Drug companies sponsored talks are often biased in favour of their products' (61.4\% vs $69.3 \%$; $\mathrm{p}=0.01$ ) and 'Gifts from drug companies to pharmacists lead to increased prices of medicines' ( $14.5 \%$ vs $15.7 \%$; $p<0.001$ ). In the case of the influence of MRs on the dispensing of drugs, none of the demographic variables was associated with any statement except 'dispensing the antibiotics without prescriptions for common ailments due to drug promotion', and the significantly high proportion of the respondents in the 20-25 years age group affirm this response (29.6\% in $20-25$ years vs $9.6 \%$ in $31-35$ years; $\mathrm{p}<0.001)$.

\section{DISCUSSION}

The effects of PP on dispensing of medications cannot be discounted and ignored. So, at present it is highly needed to prepare HCPs (pharmacists and physicians) for proper handling of drugs by making them aware about the importance of proper prescribing practices and teaching about ethical guidelines for $\mathrm{DP}^{12}$ and following up with the assessment of their practices. To the best of our knowledge, this is the first study investigating the perception of pharmacists towards pharma gifts and the training they received in Pakistan.

Our study indicated that a small number of respondents was given ethical training $(26.2 \%)$ and teaching about how to handle MRs (25\%) in the future, and also a very low number was approached by MRs in the pharmacy institute $(18.1 \%)$. These results were in line with the previous results from Saudi Arabia ${ }^{2}$ and the study by Barbar Mintzes ${ }^{26}$ but was not in accordance with the results from Kuwait, which indicated that medical students were given more training about how to deal with MRs. ${ }^{27}$ This difference is due to the syllabus difference as medical students have a separate subject related to medical ethics. In contrast, pharmacy students have no such subject and no such off-syllabus training is given in pharmacy institutes. Regarding the appropriateness of gifts, gifts were considered appropriate by the pharmacy staff with the least percentage given to expensive gifts (>Rs5000, $22.2 \%)$ and accepting direct money from MRs (17.5\%) whereas stationary, educational gifts and drug samples have the most significant percentage. Hence, the participants in our study perceive such less costly promotional gifts from industry to be beneficial to patients. Previous studies similarly revealed that among pharmacists it was common to accept low-cost gifts such as stationery, free drug samples and free meals than accepting high-priced gifts; ${ }^{2}$ this phenomenon is also common in physicians. ${ }^{21}$

The finding suggests that higher age was significantly associated with appropriate teaching or because the training received by pharmacists might be attributable to the fact that new generations have been exposed to different curricula in the PharmD programme implemented in universities, than in the past. The absence of formal ethical codes governing PP in Pakistan and the relationship between HCPs and the pharmaceutical industry or that the skills for interacting with MRs may not have been integrated as part of the traditional pharmacy college curriculum. Curriculum with proper guidelines is needed for future HCPs to get them ready to play a better role as pharmacists in influencing or making drug-related choices in the face of DP, and also to make them ready for the ethical interface with drug companies or MRs as described by the guidelines. ${ }^{1}$ Teaching with new innovative ideas that involve MRs demonstrated the develepoment of higher skills in interpreting promotional information. ${ }^{28}$

A low percentage $(25 \%)$ of pharmacists perceived that information provided by MRs had educational value and that these DPs have a low influence on their practice $(17.3 \%)$. These results are not in line with previous studies in Saudi Arabia ${ }^{2}$ where a large proportion had felt that drug company sponsored talks were biased in favour of the company's products $(76.0 \%) .^{2}$ In our study, there was no significant difference between genders in considering that promotional material could be trusted ( $40.0 \%$ in men vs $38.3 \%$ in women; $p>0.005$ ), which is not in accordance with the previous study among students. ${ }^{27}$ 


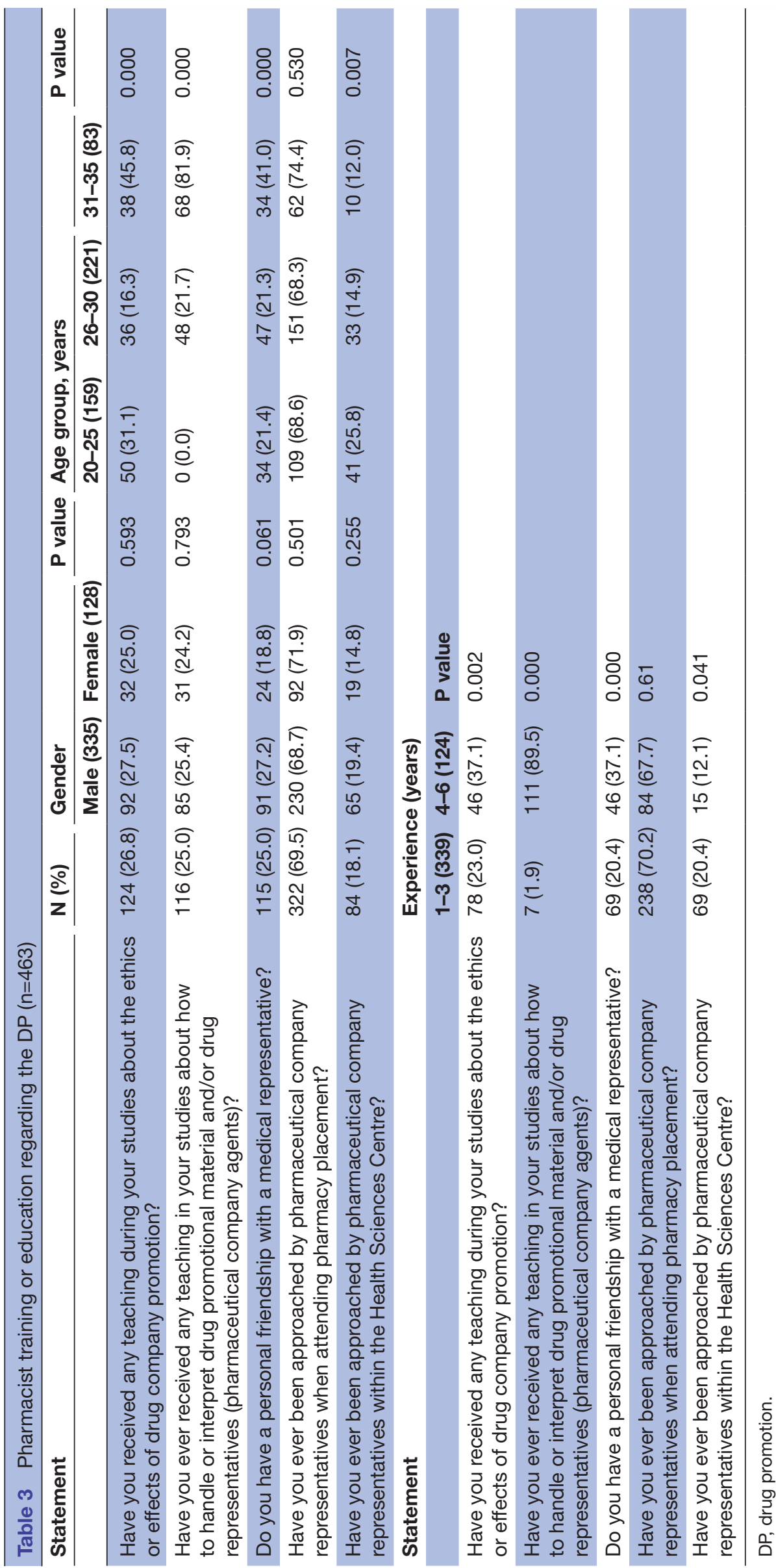




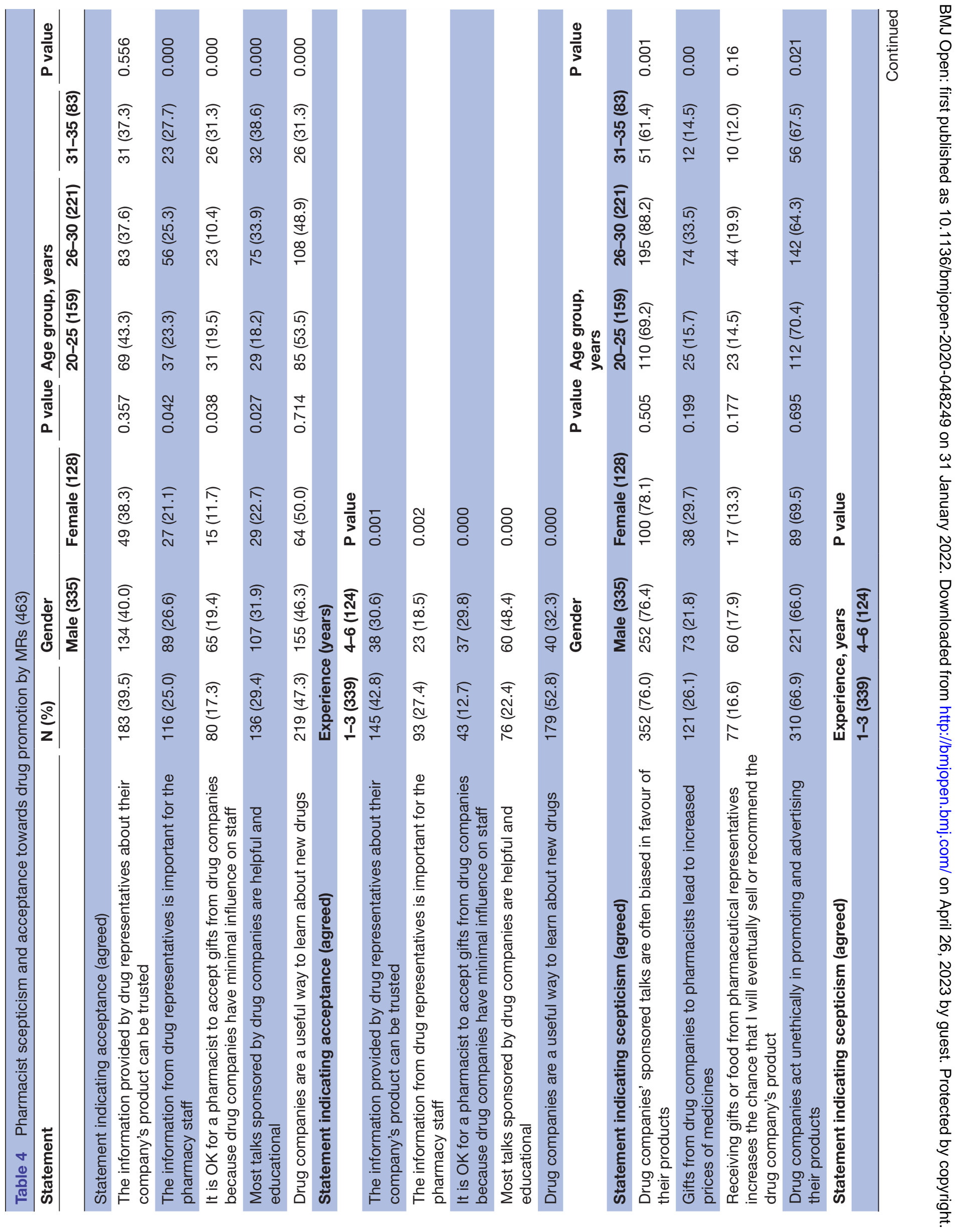




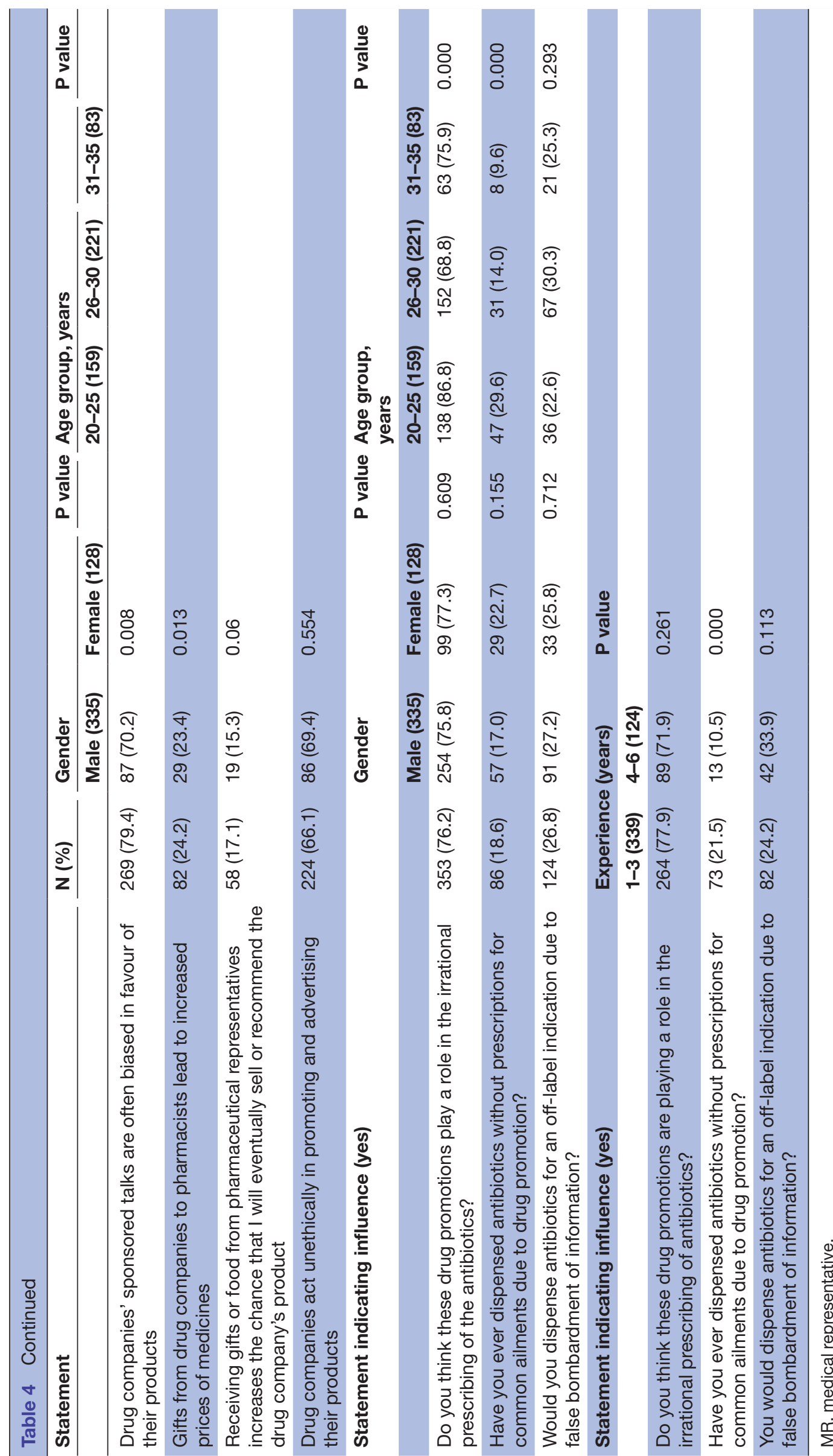


The high degree of scepticism and recognising that there is a bias in DP coupled with a low level of dispensing antibiotics without prescriptions suggests that the staff may realise the influence of DP leading to irrational prescribing. Our findings strongly suggest the implementation of discussion on ethical interaction between pharmaceutical companies and HCPs in the formal PharmD curriculum.

We aimed to target the population from a larger and wider area of Punjab. Though the sample is enough, it is not representative of all the Pakistani pharmacists. From an education perspective, there is a definite need to raise awareness among the pharmacists about the potential negative impacts of interaction between pharmacists and MRs on the cost and quality of public health. On a broader level, there is a need for system-level interventions to regulate pharmacist-industry interactions. These interventions should focus on governmental regulation and self-regulation (eg, voluntary codes of practice). The ultimate aim would be to minimise any negative effects of the pharmacist-pharmaceutical company interactions on patients and eventually on improving patient care.

\section{CONCLUSIONS}

Most of the pharmacists participating in this study believeed that it is appropriate to accept small value gifts like drug samples, stationery and printed educational materials. Recently graduated pharmacists and those with less experience had inadequate teaching/training than experienced pharmacists in PP ethics and tactics to deal with MRs. Experienced healthcare pharmacists were less approached and targeted by pharmaceutical companies and MRs. Further research should study the implementation of education about ethical promotion and appropriate interaction with MRs in the formal curriculum of the pharmacy programme to improve the ability of HCPs to promote rational use of drugs and act in the best interests of patients.

\section{Author affiliations}

${ }^{1}$ Department of Pharmacy Administration and Clinical Pharmacy, School of Pharmacy, Center for Drug Safety and Policy Research, Shaanxi Centre for Health Reform and Development Research, Xi'an Jiaotong University, Xi'an, Shaanxi, China ${ }^{2}$ The Department of Pharmacy Administration and Clinical Pharmacy, School of Pharmacy, Xi'an Jiaotong University, Xi'an, Shaanxi, China

${ }^{3}$ The Center for Drug Safety and Policy Research, Xi'an Jiaotong University, Xi'an, Shaanxi, China

${ }^{4}$ Department of Pharmacy, University of Central Punjab, Lahore, Pakistan ${ }^{5}$ Department of Pharmacy, The Islamia University of Bahawalpur Pakistan, Bahawalpur, Pakistan

${ }^{6}$ Department of Pharmacy, Bahauddin Zakariya University, Multan, Pakistan ${ }^{7}$ Department of Pharmacy Administration and Clinical Pharmacy, School of Pharmacy, Center for Drug Safety and Policy Research, The Global Health Institute, Shaanxi Centre for Health Reform and Development Research, Xi'an Jiaotong University, Xi'an, Shaanxi, China

Contributors AHG and MZ conceptualised the study. AHG, AKH, KM and SM collected the data. AHG and AS wrote the initial draft. YF supervised the whole study. YF is the gaurenter for all of the things.
Funding This work was supported by the Young Talent Support Plan; High Achiever Plan of Health Science Center; Xi'an Jiaotong University; and the Central University Basic Research Fund (2015qngz05).

Competing interests None declared.

Patient and public involvement Patients and/or the public were not involved in the design, or conduct, or reporting, or dissemination plans of this research.

Patient consent for publication Not applicable.

Ethics approval The study was approved by the Medical Research ethics Committee of Xi'an Jiaotong University, Shaanxi, China (DP 2020-13) and by the Research Ethics Committee of Superior College Lahore, Punjab, Pakistan (Pharm.2-2019).

Provenance and peer review Not commissioned; externally peer reviewed. Data availability statement Data are available upon reasonable request. None.

Open access This is an open access article distributed in accordance with the Creative Commons Attribution Non Commercial (CC BY-NC 4.0) license, which permits others to distribute, remix, adapt, build upon this work non-commercially, and license their derivative works on different terms, provided the original work is properly cited, appropriate credit is given, any changes made indicated, and the use is non-commercial. See: http://creativecommons.org/licenses/by-nc/4.0/.

ORCID iDs

Kiran Munir http://orcid.org/0000-0002-7454-7741

Amna Saeed http://orcid.org/0000-0002-0284-0260

Yu Fang http://orcid.org/0000-0002-8628-9030

\section{REFERENCES}

1 WHO. WHO ethical criteria for medicinal drug promotion. Geneva: World Health Organization, 1998.

2 Zaki NM. Pharmacists' and physicians' perception and exposure to drug promotion: a Saudi study. Saudi Pharm J 2014;22:528-36.

3 Schwartz LM, Woloshin S. Medical marketing in the United States, 1997-2016. JAMA 2019;321:80-96.

4 Pfeil W, Prantner M. Sozialbetrug und KorruptionimGesundheitswesen (Social fraud and corruption in health care). Wien: Manz, 2013.

5 Gee J, Button M. The financial cost of healthcare fraud. Portsmouth: MacIntyre Hudson/CCFS, 2014.

6 SPD AntragimDeutschen Bundestag.

KorruptionimGesundheitswesenwirksambeka mpfen (effectively combating corruption in health care), 2010. Available: https:// jusatpublicum.wordpress.com/ 2012/06/08/bundestag-korruptionim-gesundheitswesen/

7 Hugler S. Kein land in Europa istimmungegenBetrug und Korruption (NO country in Europe is immune to fraud and corruption). Dtsch med Wochenschr 2010;135:33.

8 Hall KB, Tett SE, Nissen LM. Perceptions of the influence of prescription medicine samples on prescribing by family physicians. Med Care 2006;44:383-7.

9 Health Action International. Fact or fiction: what healthcare professionals need to know about pharmaceutical marketing in the European Union - health action international, 2016. Available: https:// haiweb.org/publication/fact-or-fiction-pharmaceutical-marketing-inthe- european-union/

10 Bruno G, Frédéric B, Florian N, et al. Association between gifts from pharmaceutical companies to French general practitioners and their drug prescribing patterns in 2016: retrospective study using the French transparency in healthcare and national health data system databases. BMJ 2019;367:16613.

11 Lexchin J. Interactions between physicians and the pharmaceutical industry: what does the literature say? CMAJ 1993;149:1401-7.

12 Ashker S, Burkiewicz JS. Pharmacy residents' attitudes toward pharmaceutical industry promotion. Am J Health Syst Pharm 2007;64:1724-31.

13 Brett AS, Burr W, Moloo J. Are gifts from pharmaceutical companies ethically problematic? A survey of physicians. Arch Intern Med 2003;163:2213-8.

14 Auta A, Hadi MA, Oga E, et al. Global access to antibiotics without prescription in community pharmacies: a systematic review and meta-analysis. J Infect 2019;78:8-18.

15 Hadi MA, Karami NA, Al-Muwalid AS, et al. Community pharmacists' knowledge, attitude, and practices towards dispensing antibiotics without prescription (DAwP): a cross-sectional survey in Makkah Province, Saudi Arabia. Int J Infect Dis 2016;47:95-100. 
16 Mbonye AK, Buregyeya E, Rutebemberwa E, et al. Prescription for antibiotics at drug shops and strategies to improve quality of care and patient safety: a cross-sectional survey in the private sector in Uganda. BMJ Open 2016:6:e010632.

17 Hoxha I, Malaj A, Kraja B, et al. Are pharmacists' good knowledge and awareness on antibiotics taken for granted? the situation in Albania and future implications across countries. J Glob Antimicrob Resist 2018;13:240-5.

18 Vazquez-Lago JM, Lopez-Vazquez P, López-Durán A, et al. Attitudes of primary care physicians to the prescribing of antibiotics and antimicrobial resistance: a qualitative study from Spain. Fam Pract 2012;29:352-60.

19 Haseeb A, Bilal M. Prevalence of using non prescribed medications in economically deprived rural population of Pakistan. Arch Public Health 2016;74:1.

20 Lewin-Fetter V. Pharmaceutical representatives. Lancet 1997;350:1784.

21 Saito S, Mukohara K, Bito S. Japanese practicing physicians' relationships with pharmaceutical representatives: a national survey. PLoS One 2010;5:e12193.
22 Jawaid M, Ahmed SJ. Pharmaceutical digital marketing and its impact on healthcare physicians of Pakistan: a national survey. Cureus 2018;10:e2789.

23 Rohra DK, Gilani AH, Memon IK, et al. Critical evaluation of the claims made by pharmaceutical companies in drug promotional material in Pakistan. J Pharm Pharm Sci 2006;9:50-9.

24 Wikipedia. List of Tehsils Punjab, Pakistan, 2020. Available: https:// en.wikipedia.org/wiki/List_of_tehsils_of_Punjab,_Pakistan

25 Wikipedia. Punjab, Pakistan, 2020. Available: https://en.wikipedia. org/wiki/Punjab, Pakistan

26 Mintzes B. Educational initiatives for medical and pharmacy students about drug promotion: an international cross-sectional survey. Geneva: World Health Organization/Health Action International, 2005.

27 Ball D, Al-Manea S. Exposure and attitudes to pharmaceutical promotion among pharmacy and medical students in Kuwait†. Pharmacy Educ. 2007;7:303-13.

28 Wilkes MS, Hoffman JR. An innovative approach to educating medical students about pharmaceutical promotion. Acad Med $2001 ; 76: 1271-7$ 